\title{
Transthoracic ultrasonography for the immunocompromised patient. A pilot project that introduces transthoracic ultrasonography for the follow-up of hematological patients in Romania
}

\author{
IOANA FRINC ${ }^{1,2}$, PETRU ILIES $^{3}$, FLORIN ZAHARIE $^{4}$, DELIA DIMA $^{1}$, ALINA TANASE $^{5}$, \\ LJUBOMIR PETROV ${ }^{1}$, ALEXANDRU IRIMIE $^{4}$, CRISTIAN BERCE $^{4}$, COSMIN LISENCU $^{4}$, \\ IOANA BERINDAN-NEAGOE ${ }^{6}$, CIPRIAN TOMULEASA ${ }^{1,2}$, ANCA BOJAN AN $^{1,2}$ \\ ${ }^{1}$ Department of Hematology, "Ion Chiricuță’" Oncology Institute, Cluj-Napoca, Romania \\ ${ }^{2}$ Department of Hematology, "Iuliu Hațieganu" University of Medicine and Pharmacy, Cluj-Napoca, Romania \\ ${ }^{3}$ Department of Internal Medicine, $5^{\text {th }}$ Medical Clinic, Cluj-Napoca, Romania \\ ${ }^{4}$ Department of Surgery, "Iuliu Hațieganu” University of Medicine and Pharmacy, Cluj-Napoca, Romania \\ ${ }^{5}$ Department of Stem Cell Transplantation, Fundeni Clinical Institute, Bucharest, Romania \\ ${ }^{6}$ Department of Genetics, "Ion Chiricuță” Oncology Institute, Cluj-Napoca, Romania
}

\begin{abstract}
In the past decade, there has been significant progress in clinical hematology with the discovery of targeted molecules and thus the achievement of both hematologic and molecular responses. Nevertheless, chemotherapy remains the treatment of choice for many types of hematological malignancies. Aggressive chemotherapy leads to immunosuppression, accompanied by a high rate of infections and an increased rate of treatment-related mortality. Invasive fungal infections as well as more common bacterial and viral infections are frequent in immunocompromised patients as they are difficult to diagnose and treat. Pleuropulmonary infections in immunocompromised patients are diagnosed using clinical examination, imaging and laboratory tests. Many laboratory tests are run for several days before a final result is given and are expensive. Computer tomography is a reliable technique, but it is encumbered by high irradiation and high cost, and can assess lesions larger than $1 \mathrm{~cm}$. Transthoracic ultrasound is a modern method, used in the diagnostic algorithm of pleuropulmonary pathology. It allows the diagnosis of small lesions, can be performed at the patients' bedside, with acceptable costs and no irradiation. A fast, informed and accurate medical decision is essential for a favorable outcome in immunosuppressed patients with an adjacent infection. In the current case series we present the implementation of a new protocol for the follow-up of immunocompromised patients using transthoracic ultrasonography, of great potential use in the clinic.
\end{abstract}

Keywords: hematological malignancies, immunosuppression, transthoracic ultrasound, antibiotics, antifungal treatment.

\section{INTRODUCTION}

Significant progress has been made in clinical hematology in the past decade, that allowed more aggressive treatment options including systemic chemotherapy, autologous, allogeneic or even haploidentical stem cell transplantation [1,2]. All these therapeutic tools have improved the overall survival, but also the risk of therapy-related mortality due to infections. Despite recent progress in clinical hematology, infections still remain the main cause of mortality and morbidity in the immunocompromised patients. Most of the hematological patients are immunocompromised, at high risk of infection, which can rapidly be fatal. This risk is correlated with the hematological disease, patient's age, associated comorbidities, as well as the type of chemotherapy. The patient may thus develop bacterial, fungal or viral infections, frequently localized in the lung and/or pleura, with great potential blood dissemination and a possible rapid and unfavorable evolution [3-6]. Any delay of the correct clinical management can change the patient's prognostics, often of dismal outcome. Thus, a fast medical intervention is essential for the favorable outcome.

The diagnostics of pleuropulmonary complications is based on the clinical examination, chest $\mathrm{X}$-rays, computer tomography (CT) and specific laboratory test (inflammatory tests, galactomannan antigen determination, cultures from sputum or pleural effusion). All these methods have a low specificity, with a high rate of false positive tests [7]. Transthoracic ultrasound is a new, valuable, sensitive and efficient diagnostic method for pleuropulmonary complications, a good alternative for CT examination. The method can be used to evaluate the complex pathology of pulmonary parenchyma, pleura, mediastinum and thoracic wall. The costs are acceptable and there is no irradiation risk. CT examination is often difficult for many hematological patients due to their clinical status, but ultrasound can be performed at the patients' 
bed side. Transthoracic ultrasound can also be used for invasive procedures such as thoracocenthesis, pleural drainage, pleural or pulmonary biopsy, as well as lymph node biopsy. Any type of ultrasound machine and any type of probe can be used for thoracic examination. The examination can begin with a 2-5 MHz curve probe and can continue for accuracy with a 7.5-10 MHz linear probe. Thoracic ultrasonography can assess lesions smaller than $1 \mathrm{~cm}$ for the pulmonary parenchyma and less than $100 \mathrm{~mL}$ of pleural effusion. Due to no risk of irradiation and accessibility, the ultrasound examination can be performed on a daily basis [8-14]. Recent recommendations from both the European and American Societies of Hematology suggest the reduction of excessive, repeated, sometimes useless irradiation for hematological patients. We present a report of a case series of patients diagnosed in our clinic during May-July 2016, treated for various hematological malignancies, immunosuppressed who were afterwards diagnosed with either bacterial or fungal infections. Thus, we report the introduction of a new and modern algorithm of diagnostics for pleuropulmonary complications in immunocompromised patients by using ultrasonography in addition to classic laboratory tests and CT examination when needed.

\section{MATERIAL AND METHODS}

As a result of the collaboration between "Iuliu Hațieganu" University of Medicine and Pharmacy, "Ion Chiricuță" Oncology Institute and the Municipal Clinical Hospital, all from ClujNapoca, our team aims to assess the efficacy of transthoracic ultrasonography for the diagnosis of pleuropulmonary complications in hematological patients that undergo chemotherapy or a stem cell transplantation. We aimed to compare ultrasonography to computer tomography, with the purpose of introducing this new and feasible protocol in Romania, that will be implemented at the "Ion Chiricuță" Oncology Institute. The study involves patients diagnosed with a hematological malignancy and treated with standard-of-care chemotherapy, that are later on considered as immunosuppressed patients and at high risk of developing a pleuropulmonary complication, especially an infectious one. After clinical examination, we have used two methods of diagnostic imaging (computer tomography and ultrasonography, both to confirm the efficiency and for comparing the efficiency band sensitivity. Specific laboratory assays have been used to investigate the patients: C-reactive protein, test Galactomannan, cell cultures from blood or other biological products. These two imaging methods have later on been also used to determine the clinical evolution of the patients. Subsequently, the results were analyzed, centralized and correlated in order to determine the most effective, rapid and accurate diagnosis of pleuralpulmonary infections in hematological patients. This is crucial in determining the clinical management of the patients, as well as in adapting the therapeutic decisions as to reduce mortality and increase the overall survival. All patients accepted to participate in this pilot clinical study, and signed the informed consent, in accordance to all legal and ethical regulations. We used a 6-1.9 MHz transducer with a convex sector design ultrasound for thoracic examination. More detailed images were obtained using a 12-6.2 MHz linear transducer (Tochiba Aplio 500). For CT examination, AURA 2002 computer tomography was used, with Iomeron intravenous contrast and a median irradiation dose of $54.92 \mathrm{mGy} \times \mathrm{cm}^{2}$.

\section{CASE REPORTS}

For the first case, a 64-year old woman was diagnosed with acute myeloid leukemia (AML) M0 after having been referred to our center with a high white blood cell $(\mathrm{WBC})$ count $\left(202.86 \times 10^{3} / \mu \mathrm{L}\right)$ and $95 \%$ blasts, moderate anemia $(7.5 \mathrm{~g} / \mathrm{dL})$ and thrombocytopenia $\left(46 \times 10^{3} / \mu \mathrm{L}\right)$. The peripheral blood immunophenotype revealed positivity for $\mathrm{CD} 45+(100 \%), \mathrm{CD} 33+(99 \%), \mathrm{CD} 117+(24 \%)$, CD64 + (63\%), MPOcy + (99\%), HLA-DR - (5\%), CD34 - $(0 \%)$, CD13 - (1\%). The bone marrow karyotype was normal 46, XX and peripheral blood NPM1 type A mutation was positive. The chest $\mathrm{X}$-ray and ultrasound of abdomen were both normal. Initially, she was treated with hydroxyurea, with a good hematological response. During the initial treatment with hydroxyurea, the patient presented high fever and possible pneumonia. Empiric antibiotherapy with $3^{\text {rd }}$ generation cephalosporines and antifungal medication were administered. The patient's evolution was unfavorable despite aggressive treatment. At the moment, a thoracic CT was performed and a right postero-lateral lung abscess of $7 \mathrm{~cm}$ and right pleural effusion were diagnosed (Figures 1 A-C). 


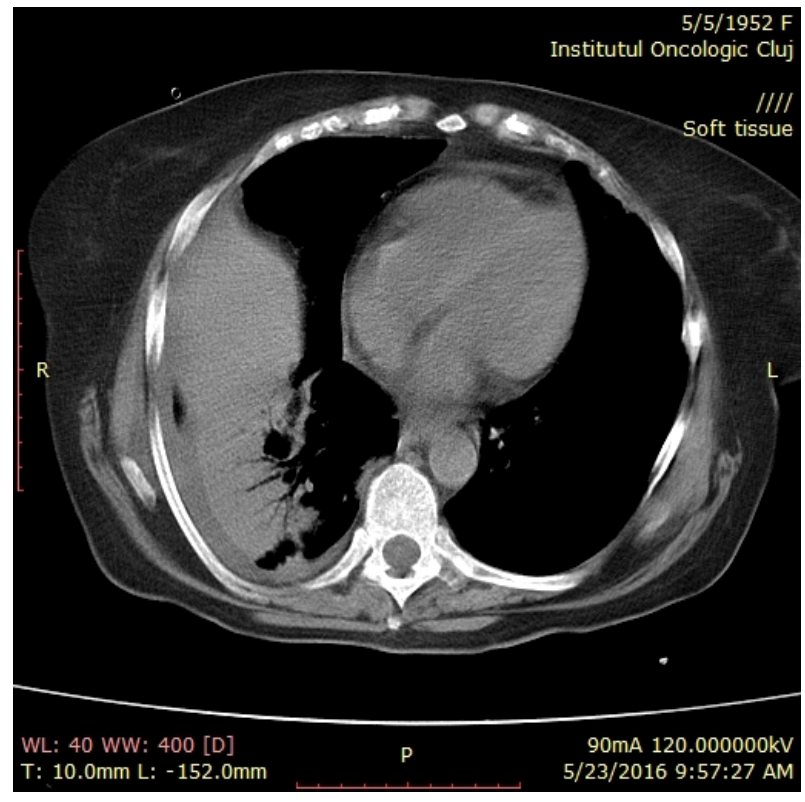

Figure $1 \mathrm{~A}$. Thoracic native CT showing a condensation zone at a right postero-lateral lung, nearly subpleural in contact with the dilated bronchial, right subpleural effusion.

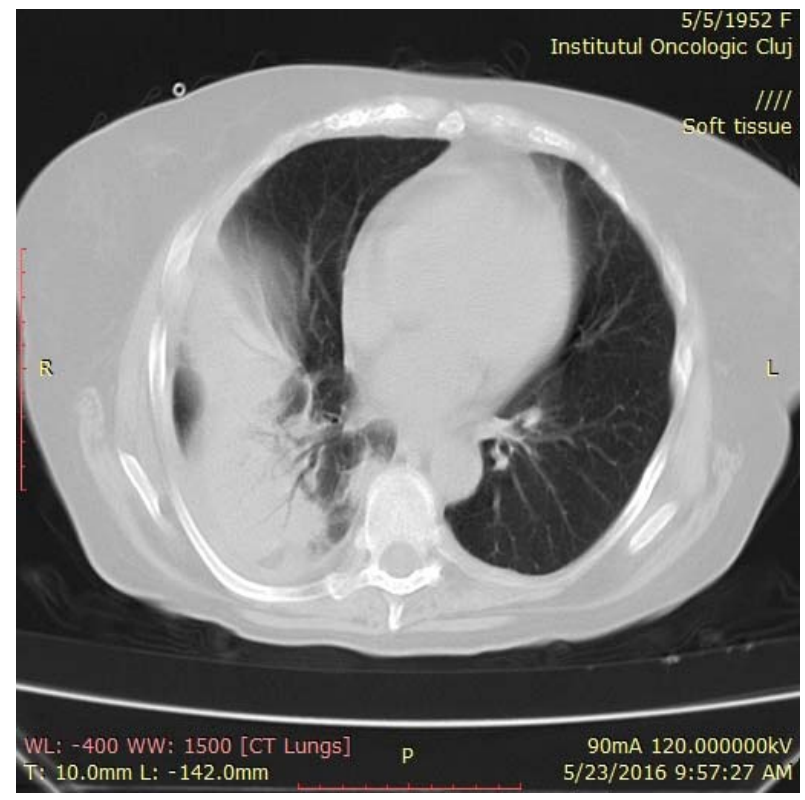

Figure 1 B. Thoracic CT with contrast substance showing bronchovascular drawing of the dilated bronchi, the condensation zone and pleural effusion in small quantities at the right subpleural pulmonary parenchyma.

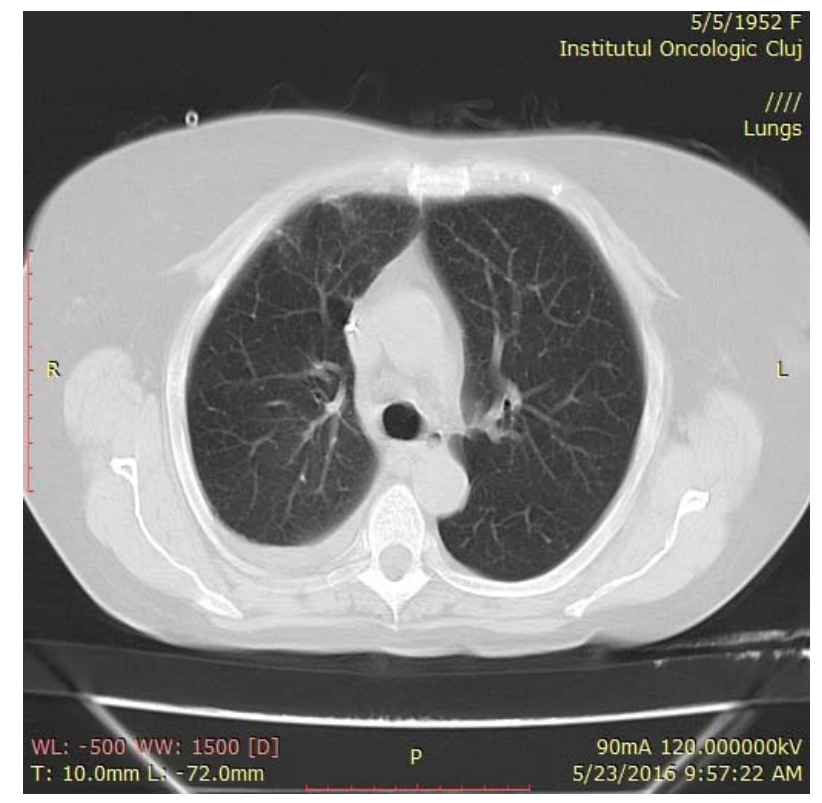

Figure $1 \mathrm{C}$. Thoracic CT with contrast substance showing right subpleural effusion.

The sputum, nose, urine or blood cultures were negative, but the pharyngeal exudates showed Candida albicans, and central line culture showed Enterococus spp. The inflammatory tests revealed high erythrocyte sedimentation rate (ESR) and fibrinogen, $\mathrm{C}$ protein reactive. The galactomannan antigen test was negative. The empirical treatment was modified with imipenem, teicoplanin and voriconazole. At the same time of CT examination, thoracic ultrasound was performed revealing bilateral pleural effusion, a right pulmonary lobe abscess, but also lower and right middle pulmonary lobe atelectasis (Figures $1 \mathrm{D}-\mathrm{H}$ ).

Finally, the antibiotic and antifungal therapy was successful with apyrexia and normal clinical examination. Unfortunately, it was not possible to evaluate with CT or thoracic ultrasound. " $3+7$ " induction chemotherapy was administered, as according to the international protocols [15]. Unfortunately, during bone marrow aplasia, the patient presented an acute ischemic stroke of the left carotid artery and succumbed. 


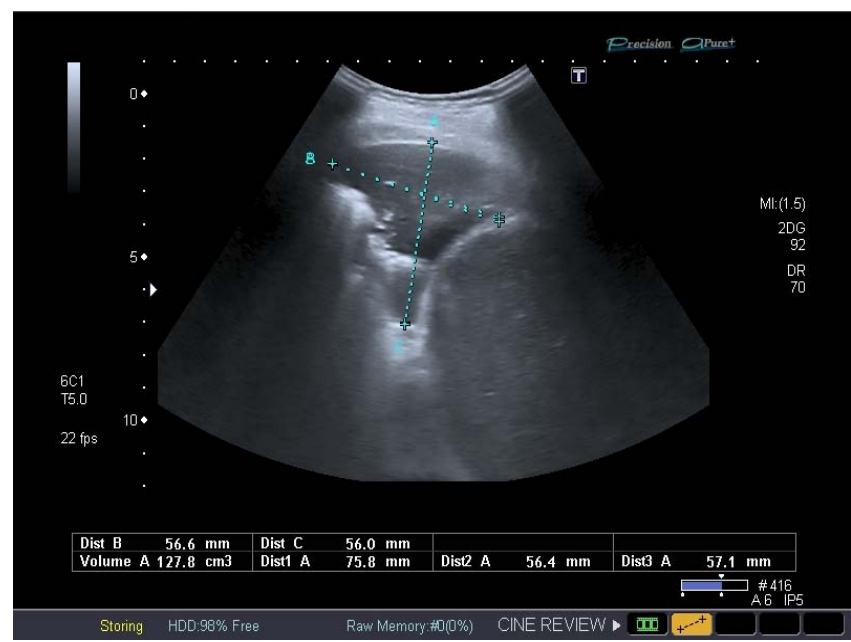

Figure 1 D. A thoracic ultrasonography, longitudinal section of the anterior right basal thorax, that shows areas of atelectasis and inferior lobe condensation areas. Right pleural collection.

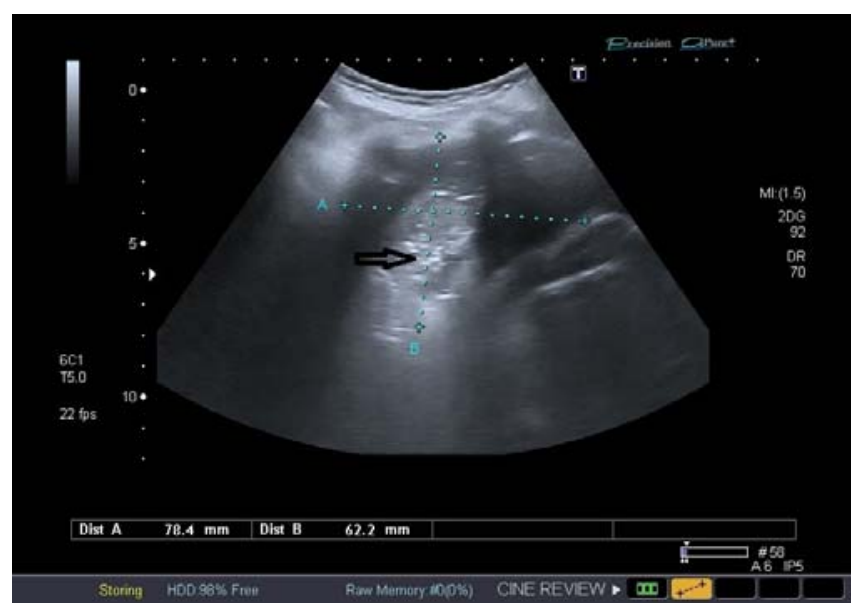

Figure $1 \mathrm{~F}$. A thoracic ultrasonography, longitudinal section of the posterior basal thorax, showing an inferior lobal posterior atelectasis and a right pleural collection.

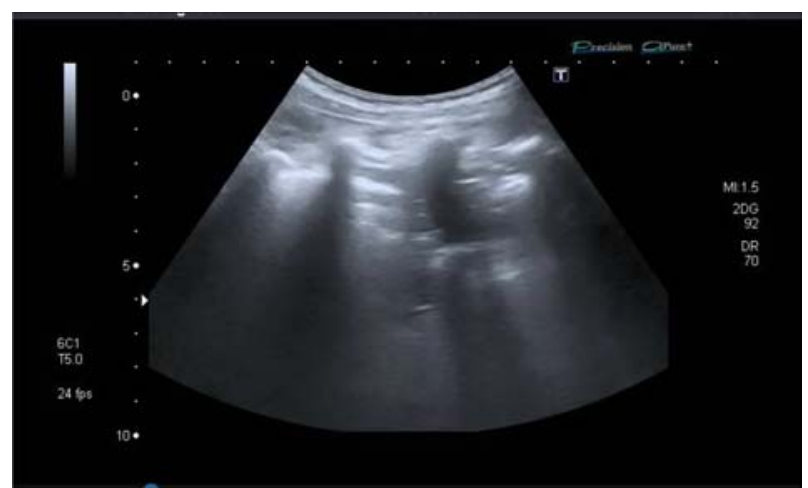

Figure 1 E. A thoracic ultrasonography, longitudinal section of the right lateral thorax, showing a pulmonary abscess.

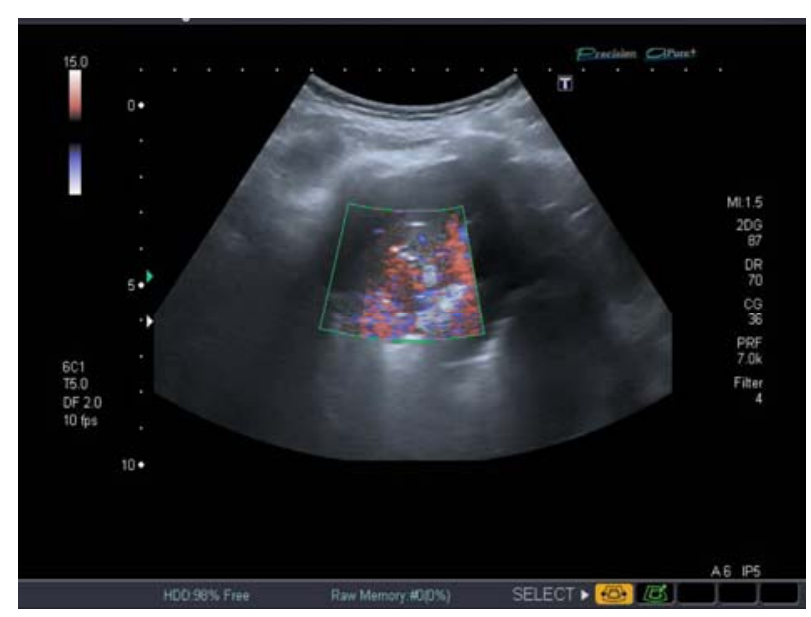

Figure 1 G. A thoracic Doppler-ultrasonography, longitudinal section of the posterior basal thorax, showing the vascularization of the atelectatic pulmonary parenchyma.

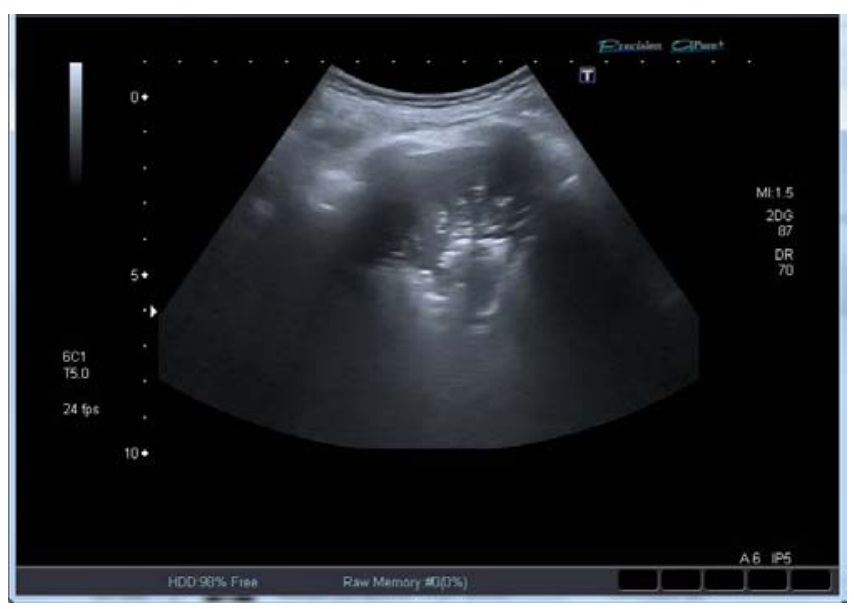

Figure $1 \mathrm{H}$. A thoracic ultrasonography, longitudinal section of the right basal thorax, showing peripheral areas of atelectasis and inferior lobal central areas of condensation. 
In conclusion, for this patient with a high-risk AML (due to high WBC and normal karyotype, despite NPM 1- type A mutation), the prognostic was poor secondary to the associated pulmonary infection at presentation, with poor response to antibiotherapy. The CT examination was useful for the diagnostic of the pulmonary abscess and right pleural effusion, but the thoracic ultrasound examination was as reliable as the $\mathrm{CT}$ examination for the diagnosis of the lung abscess. Moreover, the transthoracic ultrasonography gave the physicians a higher accuracy for the diagnosis of the bilateral pleural effusion. The right lung atelectasia was only seen using the transthoracic ultrasonography (TU). The results of both examinations were correlated as well with the inflammatory and bacteriological tests. Transthoracic ultrasonography was carried out at the patient's bed side and an initial, fast TU could probably have diagnosed the pulmonary abscess at the beginning of symptoms. This would have suggested the initiation of chemotherapy. Still, despite intensive antibiotherapy, the patient's evolution was unfavourable.

For the second patient, we diagnosed a 55 -year old woman with a non-germinal center diffuse large B cell non-Hodgkin lymphoma (DLBLC), Ann-Arbour stage IV B (with renal, hepatic, pancreatic, splenic involvement), treated



Transthoracic ultrasonography (Figures $2 \mathrm{C}-\mathrm{K}$ ) revealed bilateral pleural effusion, inferior pulmonary atelectasia and small segmentary pulmonary con- with cyclophosphamide, hydroxydaunorubicin, vincristin and prednisone (CHOP) chemotherapy, as according to the international protocol [16]. Rituximab was added after 4 cycles of CHOP chemotherapy. The patient presented with concomitant renal failure in need of hemodialysis 2-3 times/week. The initial CT examination revealed involvement of both kidneys, liver, pancreas and spleen, peritoneal adenopathies and normal thoracic examination. Prophylactic therapy with filgrastim was started on day 2 after chemotherapy. At day 10 of bone marrow aplasia, the patient presented with high fever. Blood cultures revealed Enterococcus spp, also shown in the sputum. Oral infections with Acinetobacter baumannii and cistitis with Klebsiella spp. were diagnosed. The sputum culture also revealed Candida famata. The inflammatory tests were positive with high procalcitonine at $24 \mathrm{ng} / \mathrm{mL}$ (normal range $<0.5$ ) and PCR at $30 \mathrm{mg} / \mathrm{dL}$ (normal range $<0.5$ ). Treatment with imipenem and teicoplanin, in renal doses, was started. Despite intensive antibiotherapy, the patient's general status did not improve and a pulmonary infection was the main differential diagnosis. Due to patient's status, a chest X-ray was performed that showed small right pleural effusion and no pulmonary abnormalities (Figure $2 \mathrm{~A}-\mathrm{B}$ ).



Figure 2 B. Standard chest X-ray in the lateral incidence.

densation. A perisplenic effusion was also shown on TU. Afterwards, antibiotic treatment was modified with tygacil with favourable response. 




Figure 2 C. A thoracic ultrasonography, longitudinal section of the left basal thorax, showing left pleural effusion in the posterior costo-diaphragmatic recess.
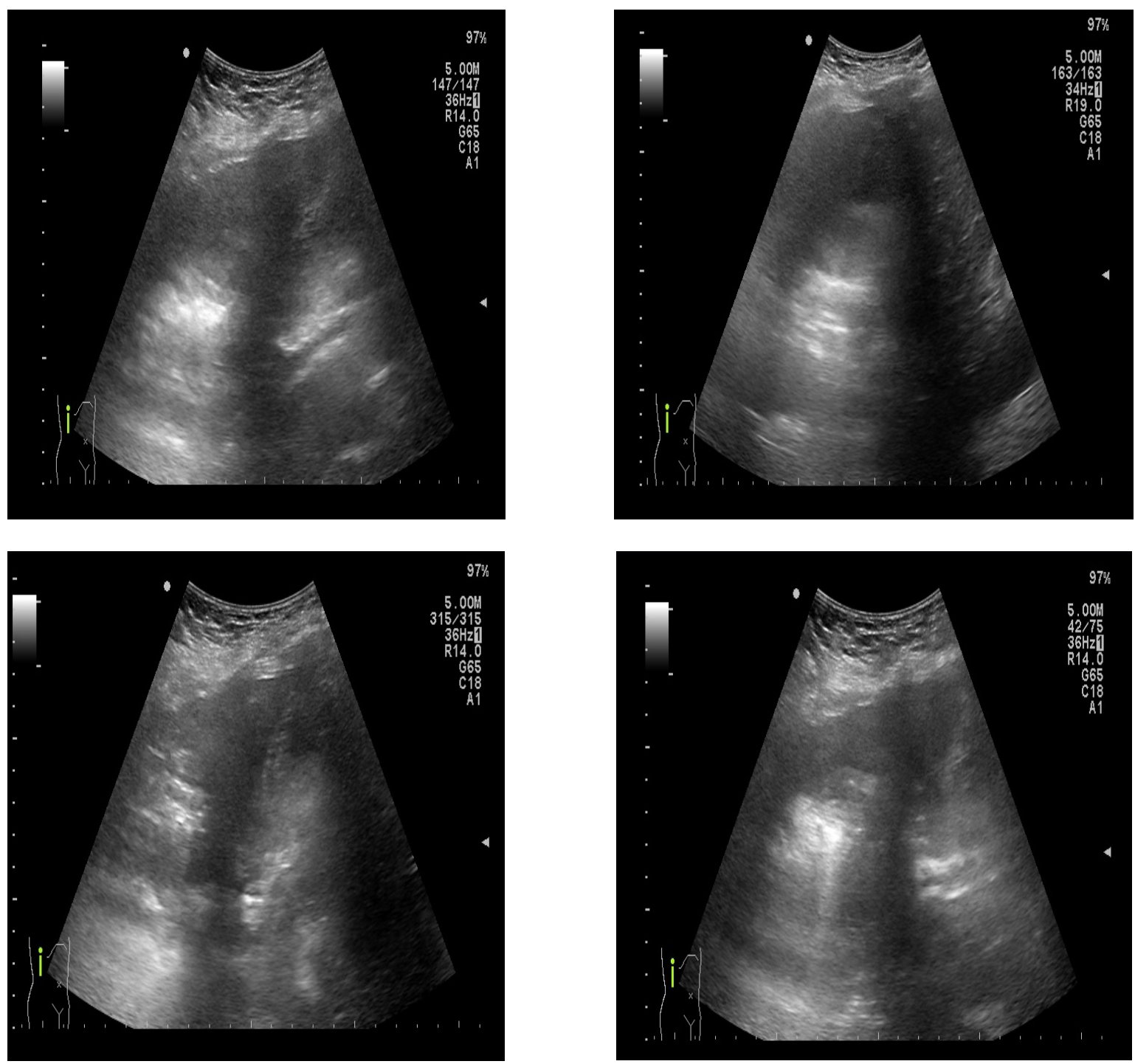

Figure 2 D, E, F, G. A thoracic ultrasonography, longitudinal section of the right basal thorax, showing right pleural effusion with pulmonary atelectasis and sub-fragmental focal condensation areas. 

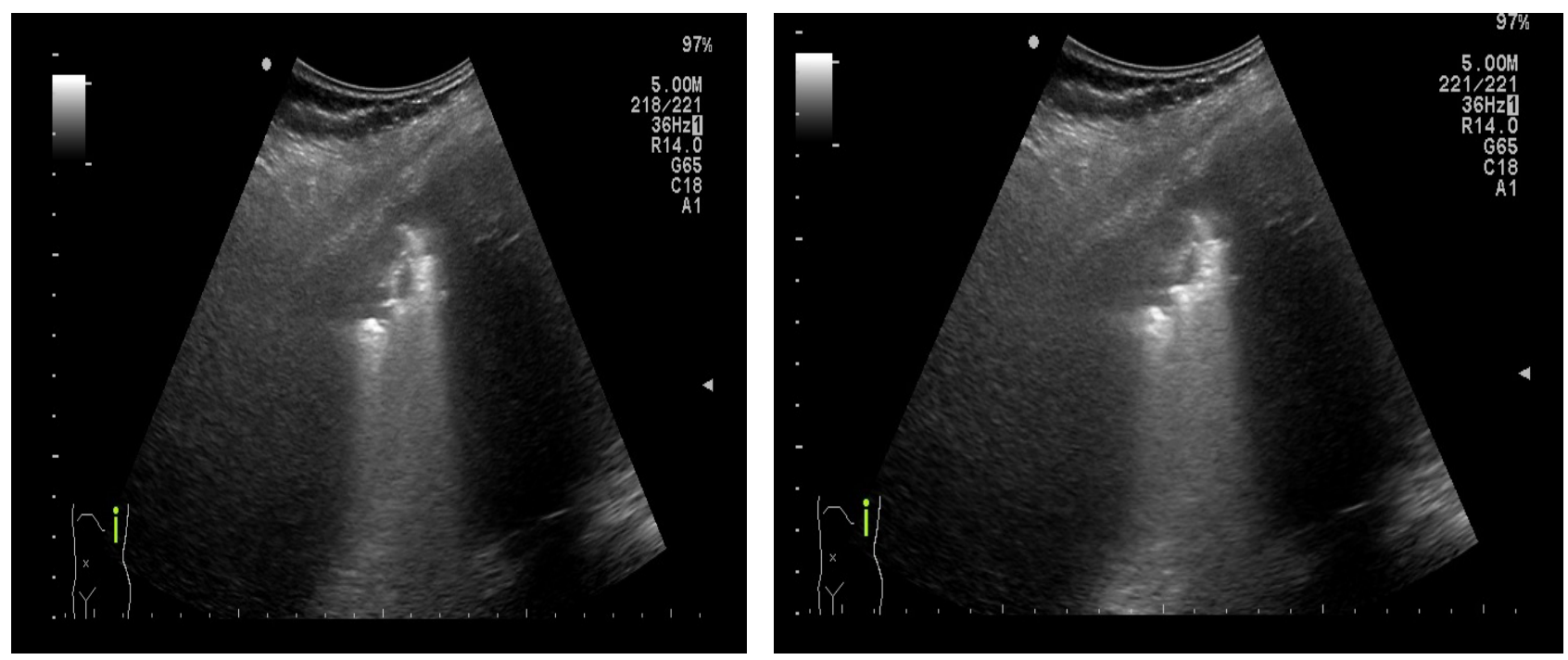

Figure 2 H, I. A thoracic ultrasonography, longitudinal section of the left basal thorax, showing areas of sub-segmental focal condensation.

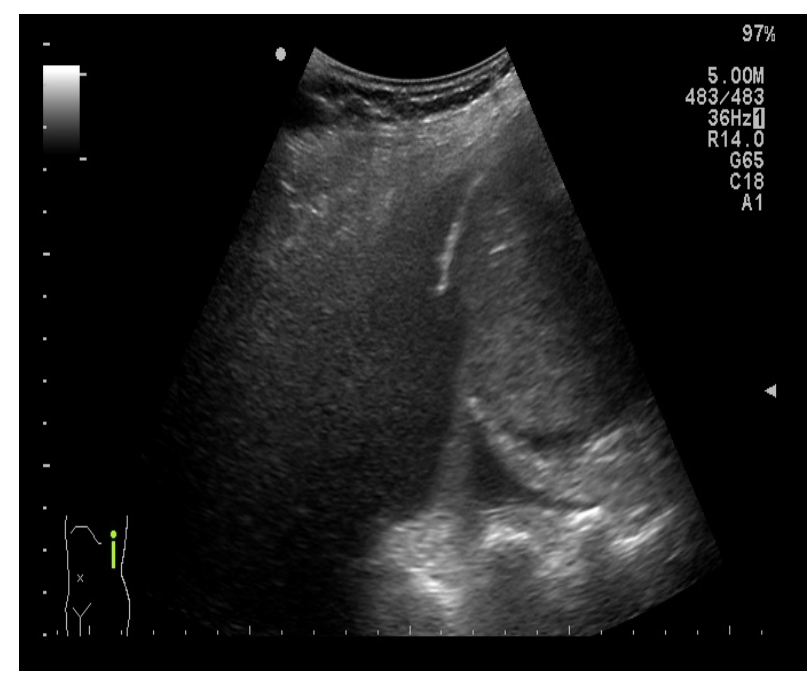

Figure $2 \mathrm{~J}$. An extended thoracic ultrasonography, longitudinal section of the left basal thorax, showing left pleural and perisplenic effusion.

In conclusion, for this patient the order was the obtaining of a good clinical outcome using CHOP chemo-therapy, as well as the fact that despite multiple disseminated infections, an intensive antibiotic treatment can be efficient if the clinical monitoring using transthoracic ultrasonography is appropriate. The ultrasound-based examination of the thorax proved to be useful and accurate. There was a slight difference between the chest X-rays and thoracic ultrasound, with TU being able to distinguish even small infectious lesions. The ultrasound imaging correlated with bacterial and inflammatory tests. The patient's case is a complex one, with an aggressive malignant disease, solved using a multidisciplinarity approach. Repeated

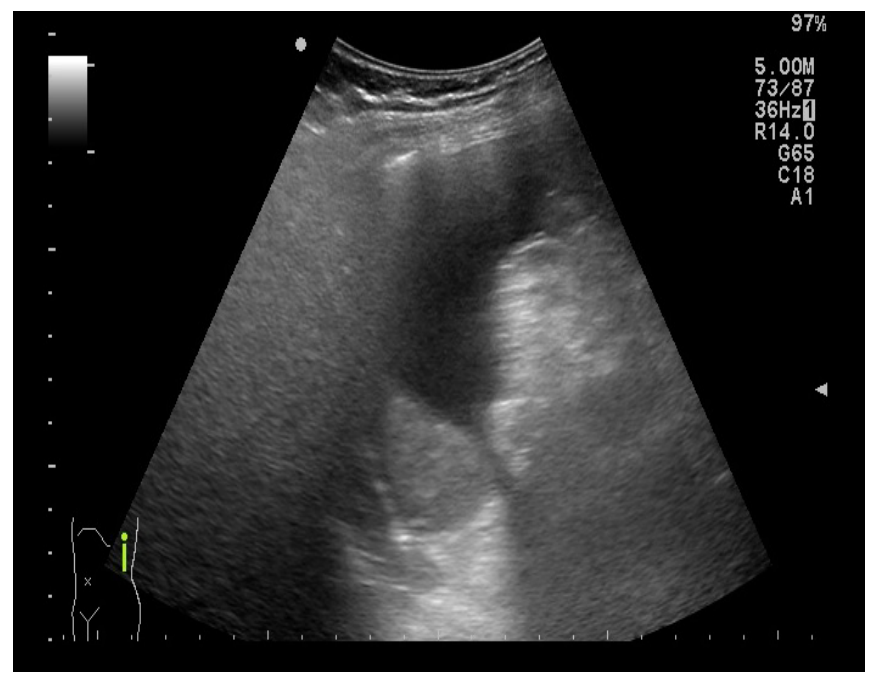

Figure 2 K. An extended thoracic ultrasonography, longitudinal section of the left basal thorax, showing perisplenic effusion.

transthoracic ultrasonographical examination was needed for this patient with multiple site infections, as the patient later continued to undergo several courses of chemo-immunotherapy.

The third case is that of a 64-year old gentleman diagnosed with a IgG kappa stage III multiple myeloma (MM). The patient had undergone two courses of chemotherapy with vincristine, doxorubicine and dexamethasone (VAD) and six more courses of chemotherapy with bortezomib, cyclophosphamide and dexamethasone (VCD), as according to international protocols [17]. In March 2016, an autologous stem cell transplantation was performed. Bone marrow aplasia secondary to the autologous transplantation was complicated with acute hemor- 
rhagic cystitis. The patient did not completely recover from the aplasia not even after three months since the autologous stem cell transplantation. Repeated bone marrow examination revelead no plasmocytic infiltration and hypocellularity with a megakaryocytic series. Corticotherapy was administered at initial dose of $1 \mathrm{mg} / \mathrm{kg}$, with subsequent tappering of the initial dosage, which led to an initial partial hematological response. The patient's evolution was complicated by repeated pulmonary infections with Candida krusei, as well as an acute enterocolitis with Clostridium difficile treated with oral vancomycine. Proper antifungal treatment with posaconazol was administered, but the patient's pulmonary infection had no favourable response. Repeated sputum culture showed Candida spp and the blood cultures showed Enterococus spp infection. The clinical evaluation of the patient was followed by a thoracic $\mathrm{CT}$, that revealed no pulmonary lesions and thickening of right pleura (Figure $3 \mathrm{~A}$ ).

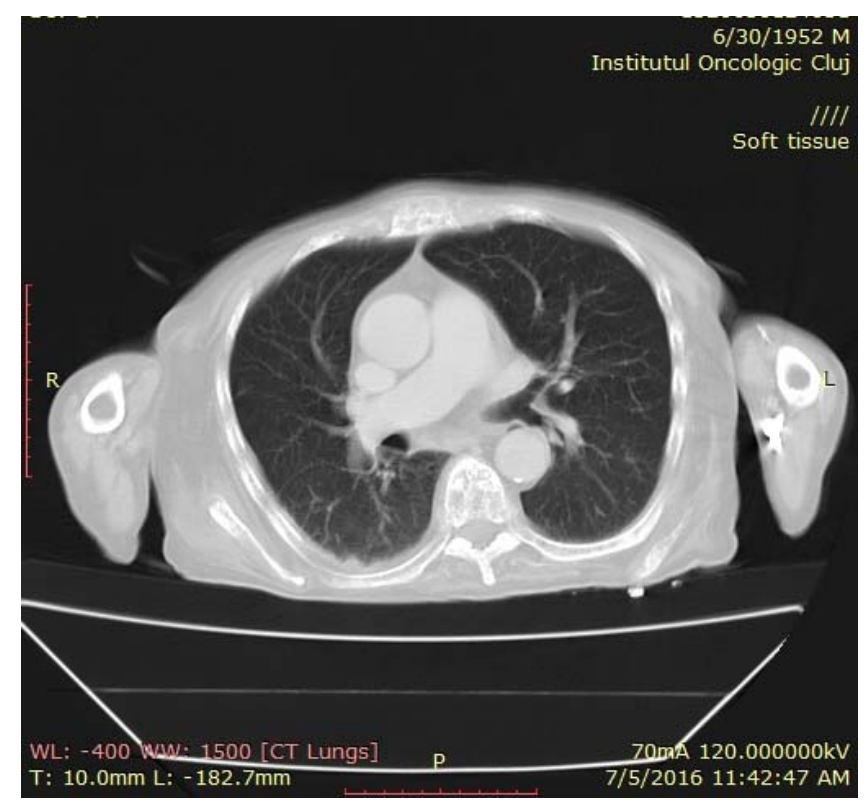

Figure $3 \mathrm{~A}$. Thoracic CT with contrast substance that shows a normal texture lung with thickening of right pleura.

The computed tomography examination was accompanied by transthoracic ultrasonography, that showed small bilateral pleural effusions, visceral pleural thickening and small inferior pulmonary lobe condensations (Figures

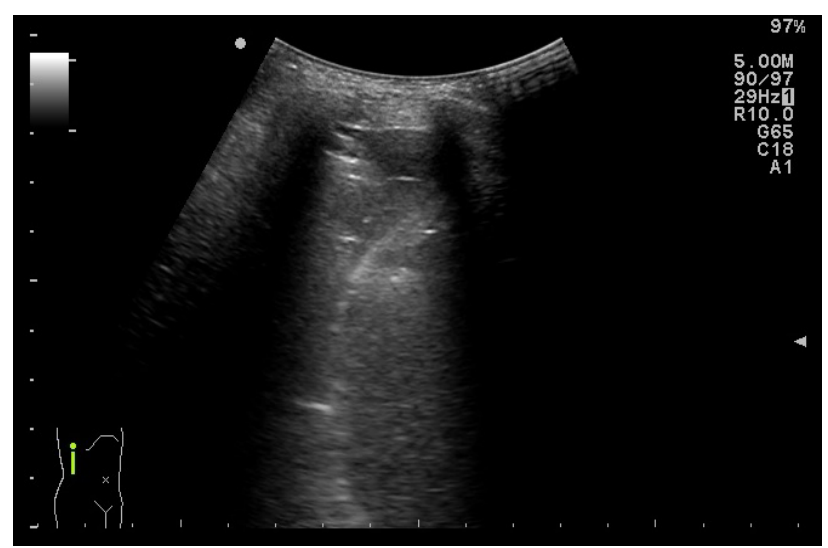

Figure 3 B. A thoracic ultrasonography, longitudinal section of the right basal posterior thorax, showing a slight pleurisy in the posterior costodiaphragmatic sinus. Areas of subsegmental focal condensation were noticed in the basal posterior region.
3 B-G). Corticosteroid treatment was discontinued and aggressive antifungal and antibiotic treatment administered. Afterwards, the patient's evolution was good with negative cultures and no respiratory symptoms.



Figure 3 C. A thoracic ultrasonography, longitudinal section of the right basal posterior thorax, showing a slight pleurisy in the posterior costodiaphragmatic sinus. Areas of subsegmental focal condensation were noticed in the basal posterior region. Visceral fibrinous pleural deposits were also revealed. 




Figure 3 D. A thoracic ultrasonography, longitudinal section of the left posterior basal thorax, showing a left pleural effusion and a focal thickening of the pleura, of lenticular shape.

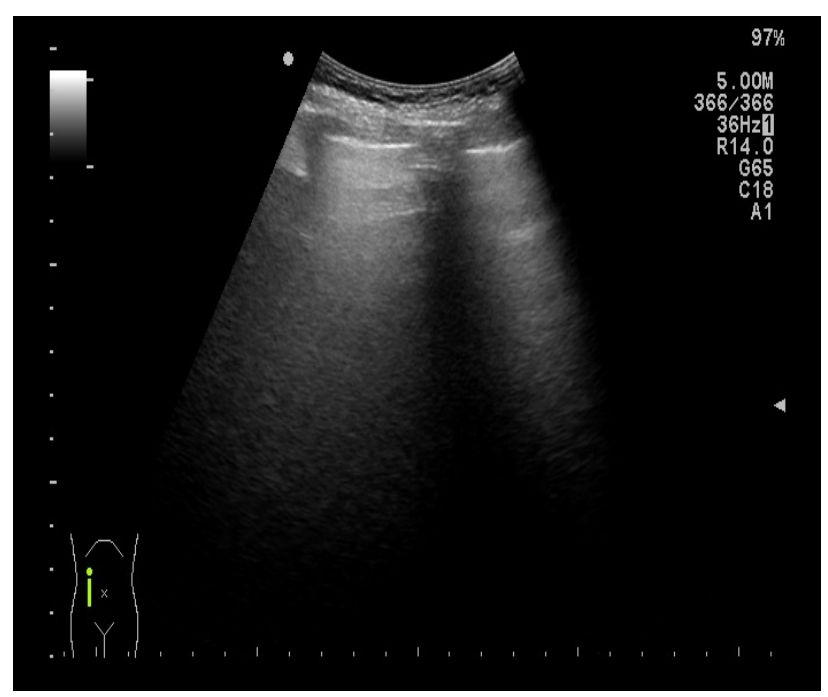

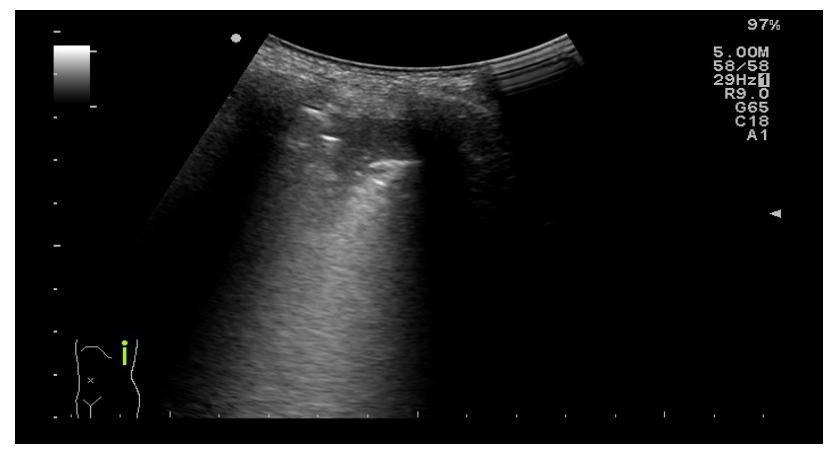

Figure 3 E. A thoracic ultrasonography, longitudinal section of the left posterior basal thorax, showing areas of subsegmental focal condensation.



Figure 3 F, G. A thoracic ultrasonography, longitudinal section of the anterior basal thorax, showing a normal right and left lung and pleura.

In conclusion, this patient, that presented with immunosuppression due to a polyclonal immuno-globuline paresis, has undergone standard chemotherapy, as well as high-dose conditioning chemotherapy for an autologous stem cell transplantation. Following the transplant, prolonged bone marrow aplasia was the main concern and corticotherapy administered, contributed to immunosuppression. All of the above justify the multiple infections that were accompanied with the severe physical status of the patient. The CT examination was useful in the exclusion of the pulmonary infection. Still, the transthoracic ultrasonography was more accurate and showed smaller pleural lesions and disseminated pulmonary condensations. The results of both examinations were correlated with the inflammatory and bacteriological tests. The TU was available at the patient's bedside and correct antibiotic and antifungal treatments made possible for this patient to overcome multiple site infections and receive additional stem cell infusion. The patient is alive and disease-free, being discharged from the clinic.

The fourth case is that of a 61-years old woman diagnosed with acute myeloid leukemia (AML) M0, after having been referred to our center with bicytopenia: white blood cell (WBC) count $\left(1.81 \times 10^{3} / \mu \mathrm{L}\right)$ and $50 \%$ blasts, moderate anemia $(9.8 \mathrm{~g} / \mathrm{dL})$ and normal platelets count $(242 \times$ $\left.10^{3} / \mu \mathrm{L}\right)$. The peripheral blood immunophenotype revealed positivity for CD45 + (100\%), CD33 + (98\%), CD117 + (23\%), CD64 + (60\%), MPOcy + (99\%), HLA-DR - (5\%), CD34 - (0\%), CD13 (2\%). Bone marrow karyotype was normal 46, XX and peripheral blood FLT3 and NPM1 type A mutation was negative. The chest $\mathrm{X}$-ray was normal, but the ultrasound of abdomen revealed hepatosplenomegaly at $3 \mathrm{~cm}$ below the costal margin. Initially, she was treated with " $3+7$ " 
induction chemotherapy. After getting hematologic remission, four courses of consolidation with high dose cytarabine were administered as according to the international protocols, getting complete remission. During the consolidation treatment regimens, the patient presented septicemia with Acynetobacter lwoffii and Methicillin-resistant Staphylococcus aureus (MRSA) confirmed by blood cultures and oral candidiasis, treated according to the protocol section for febrile neutropenia, antibiotic and fungal susceptibility adapted with complete remission. No changes were detected in the lung listeners. Due to the prognosis, we proposed allotransplant marrow from an unrelated donor, but the patient refused. After 5 months of chemotherapy sessions, during the hematological monitorization, the disease relapsed, so we decide to administrate an aggressive and salvage chemotherapy regimen -FLAG-Eto (fludarabine, cytarabine, etoposide, growth factor granulocyte, during five days). During the aplasia period the patient developed high fever. Empiric



Figure 4 A-B. Thoracic CT with contrast substance showing thickening texture broncho-pulmonary vascular emphasizing design, appearance of "frosted glass", more accentuated in the left lung.

Unfortunately, it was not possible to perform a thoracic ultrasound because the patient was transferred in the Intensive Care Unit (ICU). Subsequently, the patient presents neutropenia and thrombopenia - it was performed a bone marrow aspirate that showed refractory disease.

Afterwards, we continued the aggressive chemotherapy treatment - MEC (mitoxantrone, cytarabine, etoposide). Because the patient presented pain in the right upper quadrant with irradiation hamstrings, a thoracic and abdomen ultrasound (US) was performed revealing multiple infracentimetric hypoechogenous formations with round antibiotherapy with $3^{\text {rd }}$ generation cephalosporines, with escaladation therapy and antifungal medication (voriconazole) were administered. The patient's evolution was unfavorable despite aggressive treatment, with prolonged febrile syndrome. Blood and urine cultures were harvested with negative result, culture secretion from the central venous catheter was negative too, procalcitonin has been unreacted, $\mathrm{C}$ reactive protein (CRP) was increased with value $3 \mathrm{mg} / \mathrm{L}$. Nasal discharge culture showed Candida tropicalis multi-resistant, sensitive to echinocandins, so the caspofungin treatment was initiated, concomitant with antibiotic treatment (Meronem, Colistin, Levofloxacine) and antiviral therapy (Acyclovir). The galactomannan antigen test was negative. Despite the therapy, the fever persisted so, at that moment, a thoracic CT was performed with exudative aspect of pulmonary alveolitis (Figure 4 A-B). Biseptol treatment was initiated with suspicion of Pneumocystis carinii with fever remission and normal clinical examination.

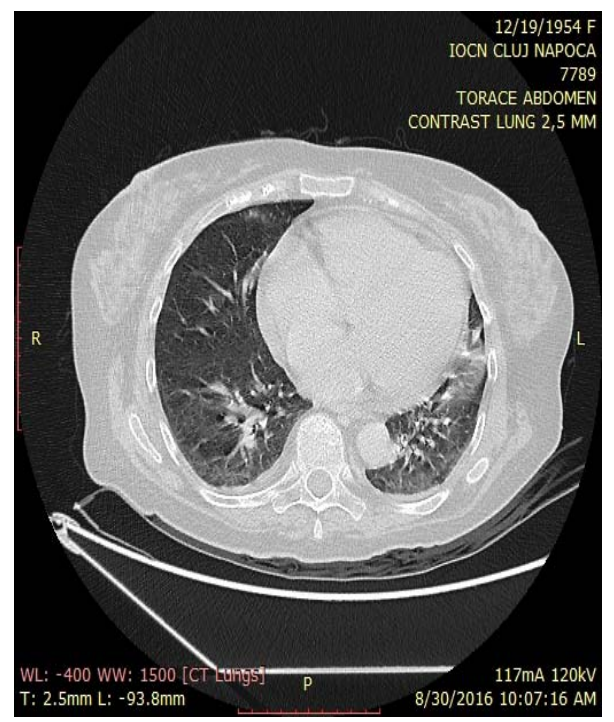

shaped echogenous center, some discrete veins located in all segments of the hepatic parenchyma, enlarged spleen volume with multiple nodular formations that look similar to the hepatic lesions, nodular lesion change, in appearance elongated oval periphery, disposed in a radial pattern, hypoechogenous, but with an echogenous center (hepatic and splenic lesion similar ones) with various sizes, chest stands lesional change basal medium and lateral in the left lung and basal posterior in the right lung (Figure $4 \mathrm{C}-\mathrm{H}$ ). All the described lesions suggest a disseminated candidaemia. 




Figure 4 C. An abdominal ultrasonography that shows a hepatic nodular lesion, hypoechogenous with echogenic center, measuring about $9 \mathrm{~mm}$, highly suggestive for Candida disseminated infection.

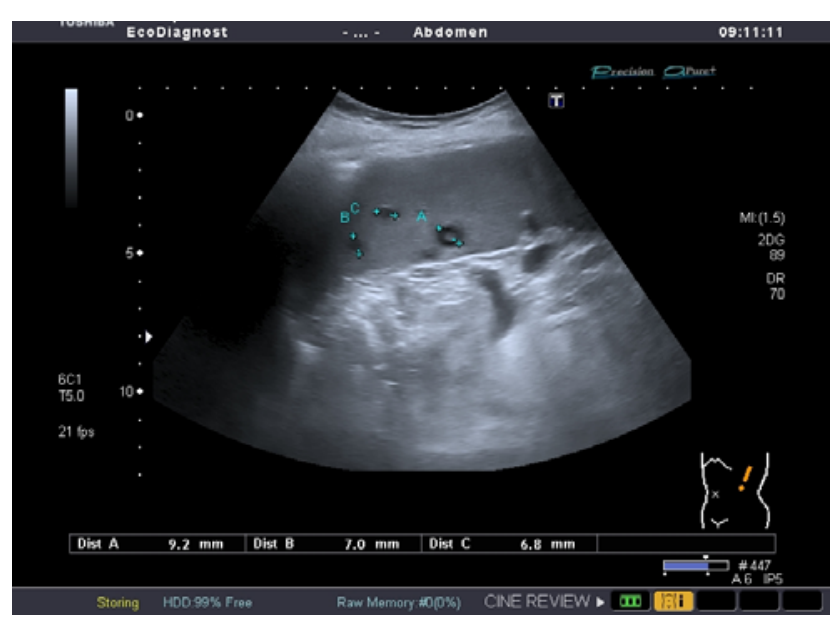

Figure 4 E. An abdominal ultrasonography that revealed a spleen longitudinal section by highlighting multiple nodular round lesions with hypoechogenous center. The aspect suggests the "bull's eyes" lesions highly suggestive for a disseminated candidaemia.

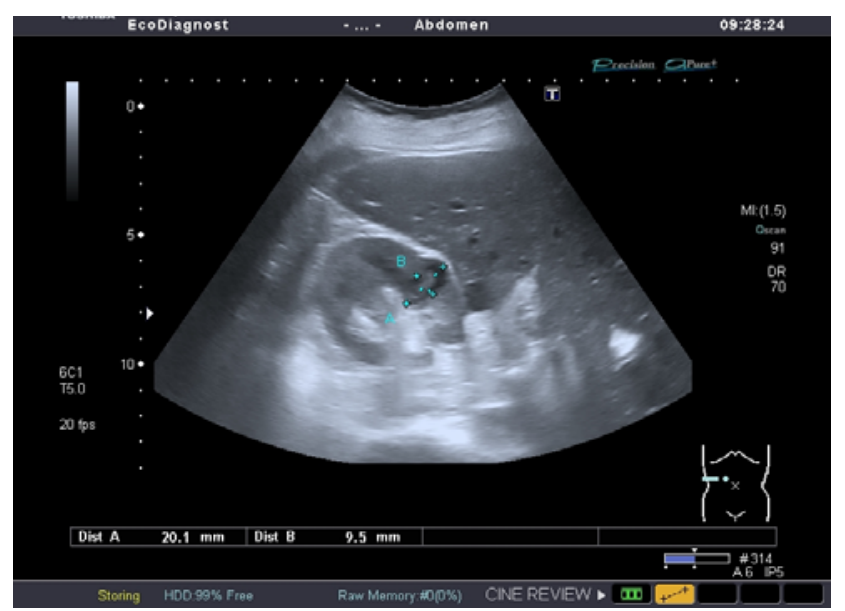

Figure 4 G. An abdominal ultrasonography that shows a hepatic nodular lesion in five segments, with a round shape, irregular contour looking hypoechogenous, peripheral predominantly with an echogenous lesion located inside, willing slightly eccentric.

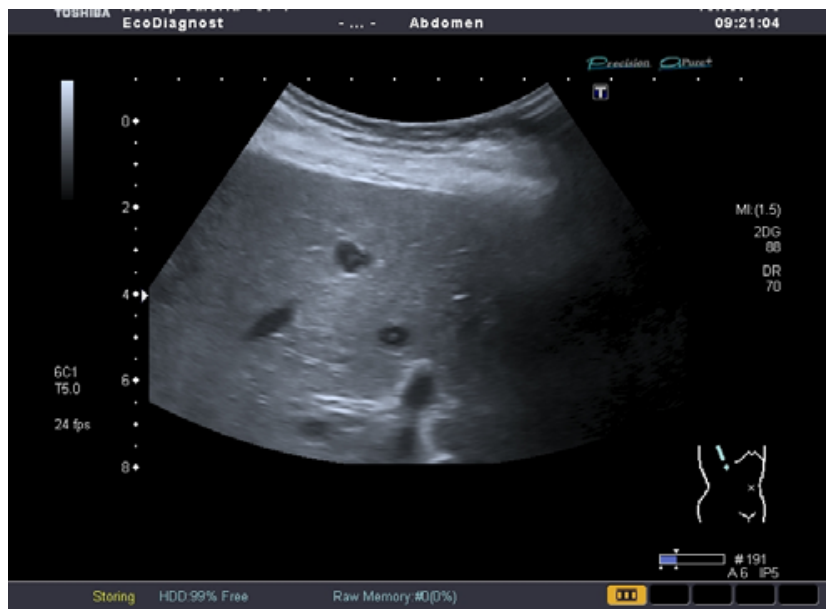

Figure 4 D. An abdominal ultrasonography that shows infracentimetric nodular lesion images in seven segments of the hepatic parenchyma with echogenous center and periphery hypoechogenous, some slightly irregular shape.

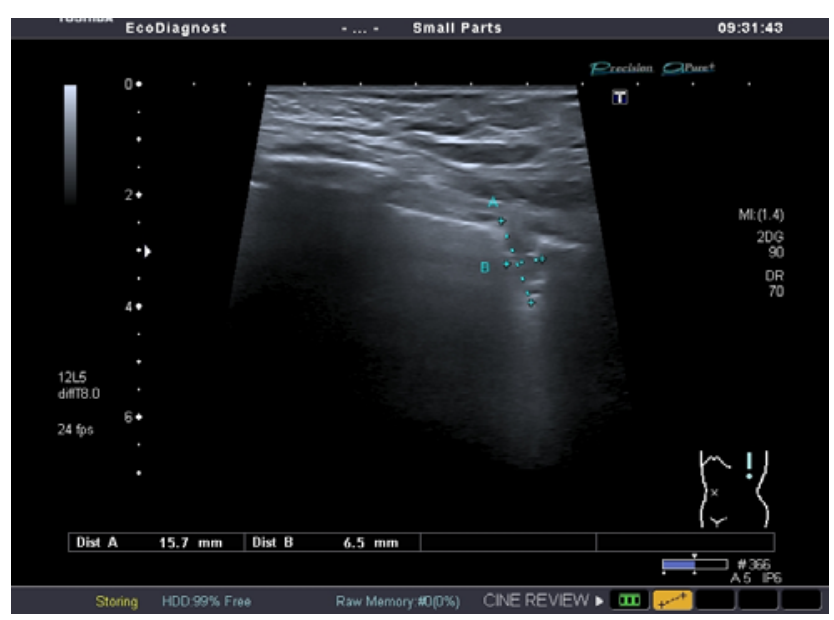

Figure $4 \mathrm{~F}$. A thoracic ultrasonography that shows a subpleural lesion condensation lateral basal side of the chest of about $15.7 / 6.5 \mathrm{~mm}$ in the right lung (possible Candida infection in the context of other abdominal disseminated and specific lesions).

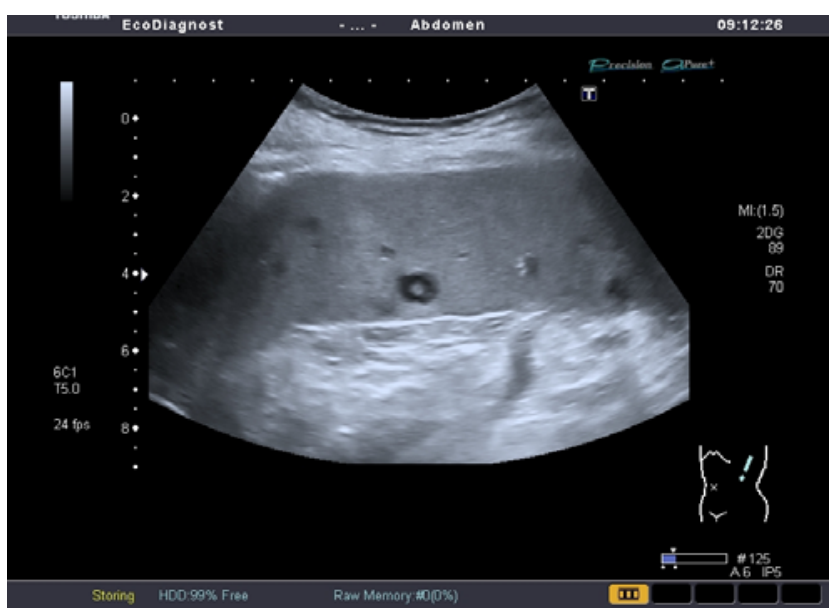

Figure $4 \mathrm{H}$. An abdominal ultrasonography that shows a nodular splenic target lesion of about $9 \mathrm{~mm}$ suggestive for Candida infection. 
US with disseminated candidaemia to the lungs, spleen and liver, result subsequently sustained by the CT examination, ultrasonography diagnosis would have been useful of the early fungal infection and constant monitoring in order to adapt the therapeutic decision. Moreover, the transthoracic ultrasonography gave the physicians a higher accuracy for the diagnosis of candidemia. The results of both examinations were correlated as well with the inflammatory and bacteriological tests. In the case of transthoracic ultrasonography could be carried out at the patient's bedside and an initial, fast TU could probably have diagnosed the disseminated candidemia at the beginning, situation that correlated with the refractory AML gives a poor prognosis to our patient .

\section{DISCUSSION}

The pilot project presented in the current paper has proven that transthoracic ultrasonography has a higher specificity in comparison with computer tomography. Very early infections can be misdiagnosed using classic CT or underdiagnosed given that the CT scan cannot detect lesions smaller than $1 \mathrm{~cm}$ located in the lung parenchyma or pleural effusion less than $100 \mathrm{~mL}$.

For the hematological immunocompromised patients, at high increased risk of disseminated infections and with possible rapid fatal outcome, despite recent progress in hematology and infectious disease, this emergent new protocol has proven so far to be reliable and efficient in the diagnosis of pleuropulmonary infections. Up to this point, the protocol is used on a routine basis in a few European centers, specialized in thoracic ultrasound. In Romania, there are only few doctors with training in transthoracic ultrasonography and hereby we report the first case series of using TU for the immunocompromised patient, a protocol that will be implemented for the first time in the country in Cluj-Napoca at the "Ion Chiricuță" Oncology Institute in collaboration with other centers of referral from the country. Our final objective is a new, modern algorithm of diagnostic for pleuropulmonary complex pathology utilizing ultrasound and specific laboratory tests, and CT examination when needed.

Conflicts of interest. All authors report no potential conflict of interest.

\begin{abstract}
Acknowledgements. Ioana Frinc, Petru Ilies and Florin Zaharie contributed equally to the current paper and are all three considered co-first authors. This work was financed by a National Research Project of the Romanian Government awarded to Ciprian Tomuleasa (PN-II-RU-TE-2014-4-1783), as well as by internal grants awarded by the "Iuliu Hațieganu" University to Ioana Frinc (internal grant for doctoral studies) and to Florin Zaharie (internal grant for assistant professors).
\end{abstract}

În ultimul deceniu s-au inregistrat progrese semnificative în hematologia clinică cu descoperirea de molecule cu acțiune țintă şi, prin urmare, obținerea răspunsului hematologic şi molecular. Cu toate acestea, chimioterapia rămâne tratamentul de elecție pentru multe tipuri de tumori maligne hematologice. Chimioterapia agresivă conduce la imunosupresie, însoțită de o rată ridicată a infecțiilor şi o rată crescută a mortalității legate de tratament. Infecțiile fungice invazive, infecțiile bacteriene comune, precum şi infecțiile virale sunt frecvente la pacienții imunocompromişi, fiind dificil de diagnosticat şi tratat. Infecții pleuropulmonare la pacienții imunocompromişi sunt diagnosticate prin examen clinic, imagistică şi analize de laborator. Multe dintre rezultatele examinărilor de laborator necesită timp pentru a obține un rezultat final şi sunt costisitoare. Tomografia computerizată reprezintă o tehnică imagistică de incredere, dar este grevată de o iradiere înaltă şi costuri ridicate, cu posibilitatea evaluării doar a leziunilor mai mari de $1 \mathrm{~cm}$. Ecografia transtoracică este o metodă modernă, folosită în algoritmul de diagnostic a patologiei pleuropulmonare. Acesta permite diagnosticul leziunilor mici, putând fi efectuată la patul pacientului, cu costuri acceptabile şi fără risc de iradiere.

Correspondence to: Dr. Ciprian Tomuleasa, Department of Hematology, "Ion Chiricuță” Oncology Institute, Cluj-Napoca, Romania, Bulevardul 21 Decembrie 1918, Nr. 73, 400124, Cluj-Napoca, Romania, Telephone: 0040741337480

E-mail: ciprian.tomuleasa@umfcluj.ro 


\section{REFERENCES}

1. TANASE A., TOMULEASA C., MARCULESCU A., BARDAS A., COLITA A, ORBAN C., et al., Haploidentical donors: can faster transplantation be life-saving for patients with advanceddisease? Acta Haematol. 2016; 135(4):211-6.

2. BRAMMER J.E., KHOURI I., GABALLA S., ANDERLINI P., TOMULEASA C., AHMED S., et al., Outcomes of haploidentical stem cell transplantation for lymphoma with melphalan-based conditioning. Biol Blood Marrow Transplant. 2016; 22(3):493-8.

3. PAGANO L., CAIRA M., CANDONI A., OFFIDANI M., FIANCHI L., MARTINO B., et al., The epidemiology of fungal infections in patients with hematologic malignancies: the SEIFEM-2004 study. Haematologica 2006; 91:1068.

4. CHAMILOS G., LUNA M., LEWIS R.E., BODEY G.P., CHEMALY R., TARRAND J.J., et al., Invasive fungal infections in patients with hematologic malignancies in a tertiary care cancer center: an autopsy study over a 15-year period (1989-2003). Haematologica 2006; 91:986.

5. HACHEM R., HANNA H., KONTOYIANNIS D., JIANG Y., RAAD I., The changing epidemiology of invasive candidiasis: Candida glabrata and Candida krusei as the leading causes of candidemia in hematologic malignancy. Cancer 2008; $112: 2493$.

6. CORNELY O.A., GACHOT B., AKAN H., BASSETTI M., UZUN O., KIBBLER C., et al., Epidemiology and outcome of fungemia in a cancer Cohort of the Infectious Diseases Group (IDG) of the European Organization for Research and Treatment of Cancer (EORTC 65031). Clin Infect Dis 2015; 61:324.

7. PAGANO L., AKOVA M., DIMOPOUlOS G., HERBRECHT R., DRGONA L., BLIJLEVENS N., Risk assessment and prognostic factors for mould-related diseases in immunocompromised patients. J Antimicrob Chemother 2011; 66 Suppl 1:i5.

8. FREIFIELD A.G., BOW E.J., SEPKOWITZ K.A., BOECKH M.J., ITO J.I., MULLEN C.A., et al., Clinical practice guideline for the use of antimicrobial agents in neutropenic patients with cancer: 2010 update by the infectious diseases society of America. Clin Infect Dis 2011; 52:e56.

9. National Comprehensive Cancer Network (NCCN) Clinical Practice Guidelines in Oncology. Prevention and treatment of cancer-related infections. Version 2. 2014. http://www.nccn.org (Accessed on July 24, 2016).

10. MAERTENS J., MARCHETTI O., HERBRECHT R., CORNELY O.A., FLUCKIGER U., FRERE P. et al., European guidelines for antifungal management in leukemia and hematopoietic stem cell transplant recipients: summary of the ECIL 3-2009 update. Bone Marrow Transplant 2011; 46:709.

11. CORNELY O.A., BOHME A., BUCHHEIDT D., EINSELE H., HEINZ W.J., KARTHAUS M., et al., Primary prophylaxis of invasive fungal infections in patients with hematologic malignancies. Recommendations of the Infectious Diseases Working Party of the German Society for Haematology and Oncology. Haematologica 2009; 94:113.

12. SEGAL B.H., FREIFIELD A.G., BADEN L.R., BROWN A.E., CASPER C., DUBBERKE E., GELFAND M., et al., Prevention and treatment of cancer-related infections. J Natl Compr Cancer Netw 2008, 6(2):122-174.

13. CICHRA A., MAKARYUS M., CHAUDHRI P., NARASIMHAN M., Ultrasound for the pulmonary consultant. Clin Med Insights Circ Respir Pulm Med. 2016; 10:1-9.

14. SPERANDEO M., FILABOZZI P., VARRIALE A., CARNEVALE V., PIATELLI M.L., SPERANDEO G., et al., Role of thoracic ultrasound in the assessment of pleural and pulmonary diseases. J Ultrasound. 2008; 11(2):39-46.

15. DOHNER H., WEISDORF D.J., BLOOMFIELD C.D., Acute myeloid leukemia. N Engl J Med. 2015; 373(12):1136-52.

16. FISCHER R.I., GAYNOR E.R., DAHLBERG S., OKEN M.M., GROGAN T.M., MIZE E.M., et al., Comparison of a standard regimen (CHOP) with three intensive chemotherapy regimens for advanced non-Hodgkin's lymphoma. N Engl J Med. 1993; 328(14):1002-6.

17. JAGANNATH S., DURIE B.G., WOLF J., CAMACHO E., IRWIN D., LUTZKY J., et al., Bortezomib therapy alone and in combination with dexamethasone for previously untreated symptomatic multiple myeloma. Br J Haematol. 2005; 129(6):776-83.

Received October 5, 2016 